\title{
Osteochondroma of the mandibular angle: Report case and literature review
}

\author{
Andrés C. Limardo, Emilio Soza, Nancy Cumpa, \\ Luis Blanco, Rubén Padín
}

\begin{abstract}
Introduction: Osteochondroma is the most common benign bone tumor. It is more frequent in long bones, by its pattern of endochondral growth. Osteochondroma in head and neck is rare. The most commonly occurring sites in the craniofacial region is the condyle. The other reported sites are mandibular symphysis, body and angle of mandible, maxillary sinus and posterior maxilla. Case Report: We present a case of a women patient that presents face asymmetry with tumor in mandibular left angle. After the surgical procedure the pathological anatomy reveals osteochondroma. Conclusion: Osteochondroma in head and neck are rare. Some cases of osteochondroma in mandibular angle are described in literature. Osteochondroma can be resected by intraoral or extraoral approaches. Only the mandibular condyle lesion require reconstruction.
\end{abstract}

Keywords: Jaw, Mandibular angle, Osteochondroma

Andrés C. Limardo ${ }^{1}$, Emilio Soza ${ }^{1}$, Nancy Cumpa ${ }^{1}$, Luis Blanco ${ }^{1}$, Rubén Padín ${ }^{1,2}$

Affiliations: ${ }^{1}$ Surgeon of Head and Neck of the Prof. A. Posadas Hospital, El Palomar, Buenos Aires, Argentina; ${ }^{2}$ Chief of Head and Neck Surgery Section of the Prof. A. Posadas Hospital, El Palomar, Buenos Aires, Argentina.

Corresponding Author: Andrés Constantino Limardo, Av Pte Illia Y Marconi s/n. El Palomar, Buenos Aires, Argentina (1684); Email: andres_limardo@hotmail.com

Received: 09 May 2017

Accepted: 30 June 2017

Published: 19 July 2017

\section{How to cite this article}

Limardo AC, Soza E, Cumpa N, Blanco L, Padín R. Osteochondroma of the mandibular angle: Report case and literature review. Case Rep Int 2017;6:3942.

Article ID: 100041CRINTAL2017

$$
* * * * * * * * *
$$

doi:10.5348/crint-2017-41-CR-9

\section{INTRODUCTION}

Osteochondroma is the most common benign bone tumor [1]. Osteochondromas in head and neck are rare. The most commonly occurring sites in the craniofacial region is the condyle, followed the coronoid process by due to the pattern of endochondral growth of the temporomandibular joint. They cause limited buccal opening and face deformity. The mandibular angle is a rare location [2]. Only three cases of osteochondroma in mandibular angle have been reported previously in literature $[3,4]$. Osteochondroma may present in solitary form or as multiple osteochondromas, syndrome known as osteochondromatosis [5].

\section{CASE REPORT}

A female of 15-year-old consults by a tumor in mandibular angle left of eight years of evolution. She does not present other clinical signs. To the physical examination a solitary stony tumor is located in mandibular angle of approximately $4 \times 3 \mathrm{~cm}$ size causing face deformity (Figure 1). The rest of the physical 
examination in the oral cavity and neck does not reveal other alterations. Mobility to mandibular and the buccal opening are not affected. Computer tomography (CT) scan with reconstruction $3 \mathrm{D}$, showed exophytic lesion in the inferior edge of left angle mandibular of approximately $45 \times 36 \times 23 \mathrm{~mm}$ displayed mixed pattern (cortical and medullar bone) in continuation with jaw without affectation in adjacent bony (Figure 2). We decided to make surgical procedure under general anesthesia. Incision is carried out to submandibular 2 $\mathrm{cm}$ below jaw respecting the marginal branch of the face nerve (Figure 3). Exophytic lesion agrees with the images of the CT displaying irregular surface with narrow base.

We dissected by subperiosteal space until healthy bony weave and the tumor was resected. Drill was made. Pathological anatomy reveals hyaline cartilaginous weave in process of calcification, but in form is observed disorganized, with some bi-nucleated chondrocytes that it covers in form of cap to spicules bony. The lesion was compatible with osteochondroma. Follow-up was made with clinical examinations and images. The patient does not present recurrences after three years of follow up.

\section{DISCUSSION}

Osteochondroma is rare in craniofacial region. It affects the long bones, but it also appears in skull base, maxilla, and in mandibular condyle process, angle, branch, body and symphysis region. The most frequent location in the jaw is condyle followed the coronoid process [2]. The limitation of buccal opening to these last locations is associated to dysfunctional pathology of the temporomandibular joint. Osteochondroma solitary is an exophytic lesion of bone that displays variable amounts of weave cartilage [1].

In some occasions, the weaves cartilage and bony display active growth, while in other this one it is diminished. By this variability, this tumor has received different denominations like cartilaginousosteo-exostosis or osteochondroma. Other causes have been attributed to the trauma. One considers to osteochondroma injuries of the development than real neoplasias. The injury, according to the WHO, is defined as an osteo cartilage exostosis with cortical and medular continuity, with bone [1]. The tumor arise from the separation of a fragment of the cartilage of epiphysis growth that is protruding through normal bone [6]. In the case of multiples, patients with osteochondromas have mutations of EXT 1 and EXT 2 genes that take part in the biosynthesis of proteoglycans heparan sulphate, involved in the epiphysis growth. The radiation can produce des differentiation of the growth cartilaginous [1]. In general, osteochondroma appears mainly in children or adolescents, without predilection by sex, although some authors consider a greater frequency in male patients. Nevertheless, has not concluded if osteochondroma is a neoplasia or reparative bony development.

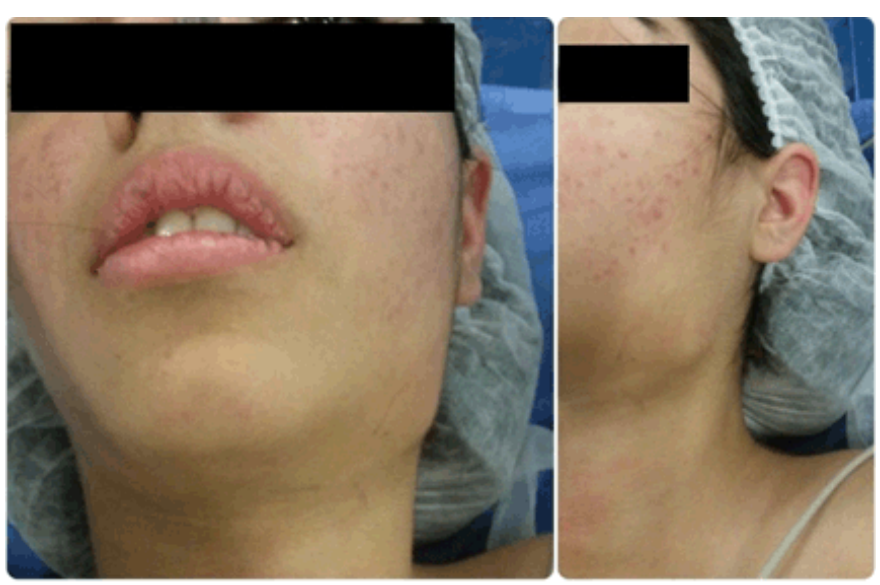

Figure 1: Stony hard solitary tumor in left mandibular angle causing face deformity.

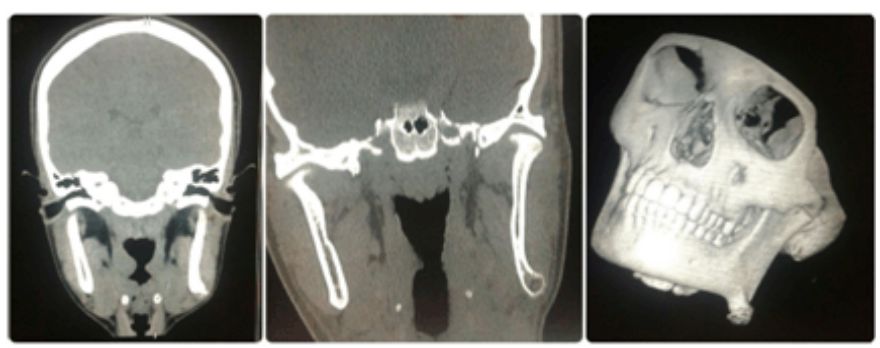

Figure 2: Computed tomography scan with reconstruction 3D looking image exophytic at the lower edge of the left mandibular

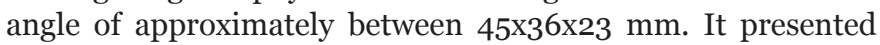
mixed pattern (cortical and medullary bone) in continuation with jaw.

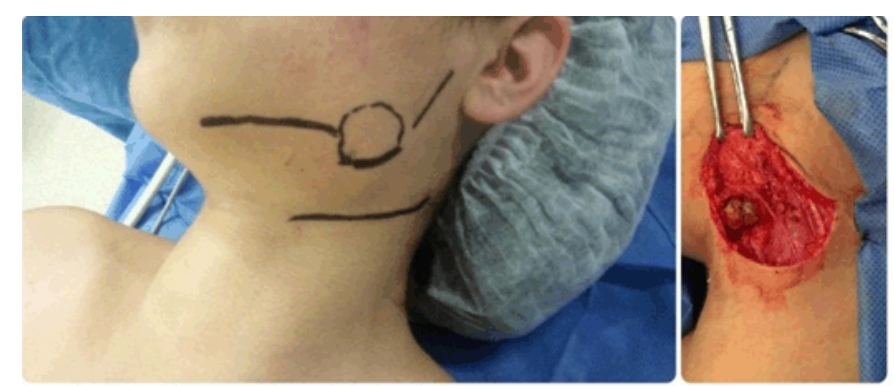

Figure 3: Submandibular approach $2 \mathrm{~cm}$ below jaw respecting the marginal branch of the facial nerve.

Lesions are asymptomatic and incidentally discovered, and if present symptoms, the most common of these is the slow development of tumor [5].

Regardless of the etiology, the goal of treatment is complete resection of the lesion and recover acceptable mouth opening in cases of involvement of the coronoid process and mandibular condyle. Always we must evaluate the mandibular dynamics [5].

As complement to clinical examination should be performed imaging study with panoramic radiographs, allowing easy access to the diagnosis. The radiographic features are quite typical, displayed an exophytic lesion with cortical and medullary continuity with the adjacent bone [7]. The base of implantation can be wide or narrow, 
representing the two types of solitary osteochondroma, the sessile and pedunculated. Computed tomography, especially with three-dimensional reconstructions, it is essential to complete the diagnosis, determine the size of the tumor, relations with neighboring structures and planning surgery [8].

Depending on the mandibular location osteochondroma can be resected by intraoral or extraoral approaches. In some cases, can be assisted resection with endoscopic video. In the case of lesions of coronoid, condylar process, body and symphysis the route of choice is intraoral video assisted whenever the mouth opening allows. Exposure of these lesions pre headset route, cervical or zygomatic poses a risk to the facial nerve branches, in addition to being a scar anti aesthetics [9].

The intraoral approach may be used if the mouth opening allows to complete removal of the tumor. The advantage is to provide a direct access to the lesion without damaging the facial nerve and leave blemishes [4].

The extra oral approaches are of choice for the body and mandibular angle. In these cases, it should enhance the dissection of the facial nerve or its branches necessary. Some authors propose that intraoral resection video assisted gives better cosmetic results and benefits for the patient. Others authors refute that these approaches can make a complete exposure of the tumor to make the resection. The disadvantages of the submandibular approach are the risk of damage to the mandibular branch of facial nerve and a scar submandibular [4].

When the coronoid process is very large and gets trapped on the zygomatic arch, the removal must be performed by a coronal approach, which has advantages such as better visualization and an acceptable scar at the hairline; moreover, when the joint reconstructions are required, they can be made temporal muscle flaps during the same procedure [10].

Regarding the treatment of mandibular lesions, there is consensus that the only therapeutic alternative is based on surgical removal without reconstruction, except in the mandibular condyle, which require reconstruction.

The described recurrence is less than $2 \%$ associated with a complete resection. If the tumors have extensive involvement of the cortical layer, especially in elderly patients with atrophic jaw, fracture may occur. Therefore, we should consider the need for orthopedic material in these cases.

\section{CONCLUSION}

Osteochondromas in head and neck are rare. Some cases of osteochondroma in mandibular angle are described in literature. It is an exophytic lesion of bone that displays variable amounts of weave cartilage. Lesions are asymptomatic and incidentally discovered, and if present symptoms, the most common of these is the slow development of tumor. Depending on the mandibular location osteochondroma can be respected by intraoral or extraoral approaches. Only the mandibular condyle lesion require reconstruction.

$* * * * * * * * *$

\section{Author Contributions}

Andrés C. Limardo - Substantial contributions to conception and design, Acquisition of data, Analysis and interpretation of data, Drafting the article, Critical revision of the article, Final approval of the version to be published

Emilio Soza - Substantial contributions to conception and design, Acquisition of data, Analysis and interpretation of data, Drafting the article, Critical revision of the article, Final approval of the version to be published

Nancy Cumpa - Substantial contributions to conception and design, Acquisition of data, Analysis and interpretation of data, Drafting the article, Critical revision of the article, Final approval of the version to be published

Luis Blanco - Substantial contributions to conception and design, Acquisition of data, Analysis and interpretation of data, Drafting the article, Critical revision of the article, Final approval of the version to be published

Rubén Padín-Substantialcontributions to conceptionand design, Acquisition of data, Analysis and interpretation of data, Drafting the article, Critical revision of the article, Final approval of the version to be published

\section{Guarantor}

The corresponding author is the guarantor of submission.

\section{Conflict of Interest}

Authors declare no conflict of interest.

\section{Copyright}

(C) 2017 Andrés C. Limardo et al. This article is distributed under the terms of Creative Commons Attribution License which permits unrestricted use, distribution and reproduction in any medium provided the original author(s) and original publisher are properly credited. Please see the copyright policy on the journal website for more information.

\section{REFERENCES}

1. Kitsoulis P, Galani V, Stefanaki K, et al. Osteochondromas: Review of the clinical, radiological and pathological features. in vivo 2008 SepOct;22(5):633-46.

2. Lim W, Weng LK, Tin GB. Osteochondroma of the mandibular condyle: Report of two surgical approaches. Ann Maxillofac Surg 2014 JulDec;4(2):215-9.

3. Moon Y, Pyon JK. Endoscopic Excision of Osteochondroma of the Mandibular Angle. Arch Plast Surg 2015 Sep;42(5):663-5. 
4. Mamatha NS, Shah A, Narayan TV, Savita JK. Osteochondroma at the angle of mandible: A rare case. J Oral Maxillofac Pathol 2015 Jan-Apr;19(1):110.

5. Yu HB, Li B, Zhang L, Shen SG, Wang XD. Computerassisted surgical planning and intraoperative navigation in the treatment of condylar osteochondroma. Int J Oral Maxillofac Surg 2015 Jan;44(1):113-8.

6. Villanueva J, González A, Cornejo M, Núñez C, Encina S. Osteochondroma of the coronoid process. Med Oral Patol Oral Cir Bucal 2006 May 1;11(3):E289-91.

7. Avinash KR, Rajagopal KV, Ramakrishnaiah RH, Carnelio S, Mahmood NS. Computed tomographic features of mandibular osteochondroma. Dentomaxillofac Radiol 2007 Oct;36(7):434-6.
8. Mehta M, White LM, Knapp T, Kandel RA, Wunder JS, Bell RS. MR imaging of symptomatic osteochondromas with pathological correlation. Skeletal Radiol 1998 Aug;27(8):427-33.

9. $\mathrm{Yu} \mathrm{HB}$, Sun H, Li B, et al. Endoscope-assisted conservative condylectomy in the treatment of condylar osteochondroma through an intraoral approach. Int J Oral Maxillofac Surg 2013 Dec;42(12):1582-6.

10. Wolford LM, Mehra P, Franco P. Use of conservative condylectomy for treatment of osteochondroma of the mandibular condyle. J Oral Maxillofac Surg 2002 Mar;6o(3):262-8.
Access full text article on other devices

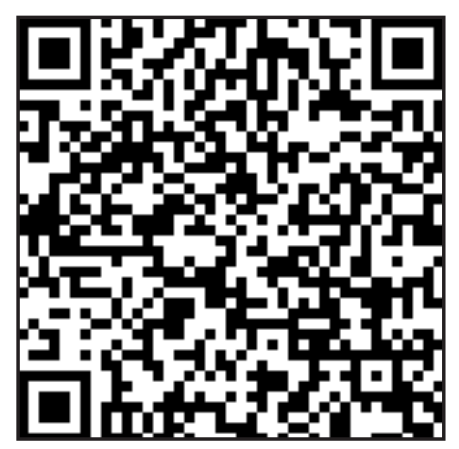

Access PDF of article on other devices

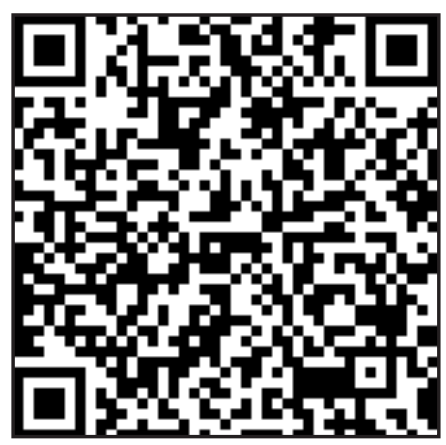

